\title{
Timing of androgen deprivation therapy use and fracture risk among elderly men with prostate cancer in the United States
}

\author{
Jennifer L. Beebe-Dimmer ${ }^{1,2 *}$, Karynsa Cetin ${ }^{3}$, Vahakn Shahinian ${ }^{4}$, Hal Morgenstern ${ }^{5}$, Cecilia Yee ${ }^{1}$, \\ Kendra L. Schwartz ${ }^{1,6}$ and John Acquavella ${ }^{3}$ \\ ${ }^{1}$ Karmanos Cancer Institute, Wayne State University, Detroit, MI, USA \\ ${ }^{2}$ Department of Oncology, Wayne State University, Detroit, MI, USA \\ ${ }^{3}$ Amgen Inc. Center for Observational Research, Thousand Oaks, CA, USA \\ ${ }^{4}$ University of Michigan Medical School, Department of Internal Medicine, Ann Arbor, MI, USA \\ ${ }^{5}$ University of Michigan School of Public Health, Departments of Epidemiology and Environmental Health Sciences, Ann Arbor, MI, USA \\ ${ }^{6}$ Department of Family Medicine, Wayne State University, Detroit, MI, USA
}

\begin{abstract}
Purpose Fractures are a recognized consequence of androgen deprivation therapy (ADT); however, less is known about the incidence of fracture in relation to the timing of ADT use or the impact of fracture on mortality in men with prostate cancer.

Methods Using data from the Surveillance, Epidemiology, and End Results-Medicare linked database, we estimated adjusted hazard ratios (aHRs) using time-dependent Cox regression for fracture incidence related to the recency of exposure and dose among prostate cancer patients on gonadotropin-releasing hormone $(\mathrm{GnRH})$ agonists, as well as mortality associated with fractures.

Results In our cohort of 80844 patients, ADT was associated with an increased rate of fracture in both non-metastatic patients $(\mathrm{aHR}=1.34 ; 95 \%$ confidence interval $[\mathrm{CI}]=1.29-1.39)$ and metastatic patients $(\mathrm{aHR}=1.51 ; 95 \% \mathrm{CI}=1.36-1.67)$. Fracture rates increased with increasing cumulative GnRH dose but decreased with increasing number of months since last use in each dose category. The mortality rate doubled for men experiencing a fracture after their diagnosis compared with that for men who did not experience a fracture $(\mathrm{aHR}=2.05 ; 95 \% \mathrm{CI}=1.98-2.12)$.

Conclusions ADT in elderly men with prostate cancer increased the incidence of fractures, and the effect appears to diminish with increasing time since the last dose of a GnRH agonist. Experiencing a fracture after the diagnosis of prostate cancer was associated with decreased survival. Copyright (c) 2011 John Wiley \& Sons, Ltd.
\end{abstract}

KEY WORDS - epidemiology; prostate cancer; GnRH agonist; orchiectomy; SEER-Medicare; mortality; skeletal-related events

Received 27 April 2011; Revised 30 August 2011; Accepted 13 September 2011

\section{INTRODUCTION}

Androgen deprivation therapy (ADT) is a common treatment for men with metastatic prostate cancer, for those with non-metastatic disease in combination with radiation therapy, as well as among patients with rising prostate-specific antigen concentrations after definitive treatment (radical prostatectomy or radiation therapy). ${ }^{1}$ With the rise in the use of ADT, there has been increasing recognition of potentially serious adverse

*Correspondence to: J. L. Beebe-Dimmer, Department of Oncology, Wayne State University, 4100 John R. Detroit, MI 48201, USA. E-mail: dimmerj@karmanos.org effects including diabetes, cardiovascular disease, osteoporosis, and fracture. ${ }^{2-5}$ It has been estimated that use of gonadotropin-releasing hormone $(\mathrm{GnRH})$ agonists among men with non-metastatic prostate cancer is associated with an annual loss of $0.6 \%$ to $4.6 \%$ in bone mineral density, with the greatest rate of bone loss occurring during the first year of therapy. ${ }^{1,6-8}$ Several lines of treatment have been shown to reverse ADT-related bone loss in patients with non-metastatic prostate cancer, including bisphosphonates, RANK ligand monoclonal antibodies, and selective estrogen receptor modulators. ${ }^{9-15}$

Although the association between ADT and fracture risk in prostate cancer has been established, 2,3,16-18 we know much less about how this risk varies as a 
function of duration of time on ADT and, for those who discontinue therapy, how risk varies with time since discontinuation. Furthermore, although ADTinduced skeletal complications clearly influence the quality of life in men with prostate cancer, a largescale investigation of the potential impact of experiencing a fracture on mortality among men with non-metastatic disease has never been conducted. ${ }^{1}$ In this investigation, using the most recent decade of data available from the Surveillance, Epidemiology, and End Results (SEER)-Medicare database, we estimate the incidence of fracture associated with both the recency of use and cumulative dose of ADT in men with prostate cancer. In addition, we estimate the relative risk of death among non-metastatic prostate cancer patients who experience a fracture.

\section{METHODS}

The SEER-Medicare dataset is a unique resource linking two population-based sources of data used to provide information about the experience of elderly patients with cancer in the USA. The SEER program, sponsored by the National Cancer Institute, is a network of population-based cancer registries that routinely collects information on patients with a new diagnosis of invasive cancer, residing within one of the registry catchment areas. SEER is composed of 18 statewide or regional cancer registries, collecting data on patient demographics, tumor histology and pathology, first course of treatment, and survival. Through linking SEER registry data to Medicare enrollment and claims files, the SEER-Medicare database provides additional information on treatment and outcomes of approximately $25 \%$ of elderly patients diagnosed with cancer in the USA. ${ }^{19}$

The eligible patients for the current investigation were diagnosed at the age of 66 years and older with primary malignant prostate cancer ( site code C61.9, International Classification of Diseases for Oncology $3^{\text {rd }}$ Edition) between 1 January 1996 and 31 December 2003, captured among 1 of 16 SEER registries (Connecticut, Hawaii, Iowa, New Mexico, Utah, Atlanta, Rural Georgia, Detroit, Seattle-Puget Sound, Los Angeles, San JoseMonterey, San Francisco-Oakland, Greater California, Kentucky, Louisiana, and New Jersey). Patients not continuously enrolled in both Part A and Part B Medicare for the 12 months prior to and following prostate cancer diagnosis were excluded in an effort to minimize the misclassification of fracture as well as other comorbidities prior to prostate cancer diagnosis. Patients who were members of a health maintenance organization (HMO) at any point in the 12-month period prior to and following prostate cancer diagnosis were also excluded to avoid the potential for missing information due to claims not processed through Medicare. Patients receiving ADT prior to prostate cancer diagnosis were excluded, as well as patients with a fracture claim within 1 month of cancer diagnosis and those missing important clinical data, leaving a total study population of 80844 men available for analysis (Figure 1).

Exposure to ADT was based on the documentation of at least one dose of a GnRH agonist or orchiectomy after prostate cancer diagnosis. To calculate $\mathrm{GnRH}$ dose, we used the methods developed by one of our coauthors (V.S.) as recommended by the National Cancer Institute (NCI). ${ }^{2}$ Dose was calculated from each instance of a GnRH agonist injection noted on separate days for the 12-month period after diagnosis as well as the total number of doses over the followup period. Because GnRH agonists are administered as depot injections with the dosage given depending on the intended regimen (every 1, 3, and 4 months), the dosage recorded from the Medicare claims files was then converted to a once-a-month regimen. In addition, time (in months) since last use of a GnRH agonist was calculated from the month of last dose to the month of fracture or censoring.

Fracture diagnoses were identified through International Classification of Diseases, 9th revision (ICD-9) codes and extracted from the Medicare physician (carrier), inpatient, or outpatient claims files. Fractures requiring hospitalization were analyzed separately from inpatient claim files. Patients were followed for fracture until 31 December 2006, representing the end of complete follow-up for patients included in SEER-Medicare. Patient characteristics (age at diagnosis, race, and a history of osteoporosis, osteopenia, and fracture), year of diagnosis, disease characteristics (clinical tumor stage and histological grade), and treatment other than ADT (radical prostatectomy and radiation therapy) were examined for their relations with fracture incidence. We also included in our analyses a modified version of the Charlson comorbidity index, which was based on ICD-9 diagnostic and procedure codes as well as on the Healthcare Common Procedure Coding System codes for 10 conditions captured in the 12-month period prior to prostate cancer diagnosis for all cases. ${ }^{20}$ Ecologic measures of socioeconomic position were also evaluated describing the education and income level of the census tract in which the patient resided at the time of diagnosis. ${ }^{21}$ 


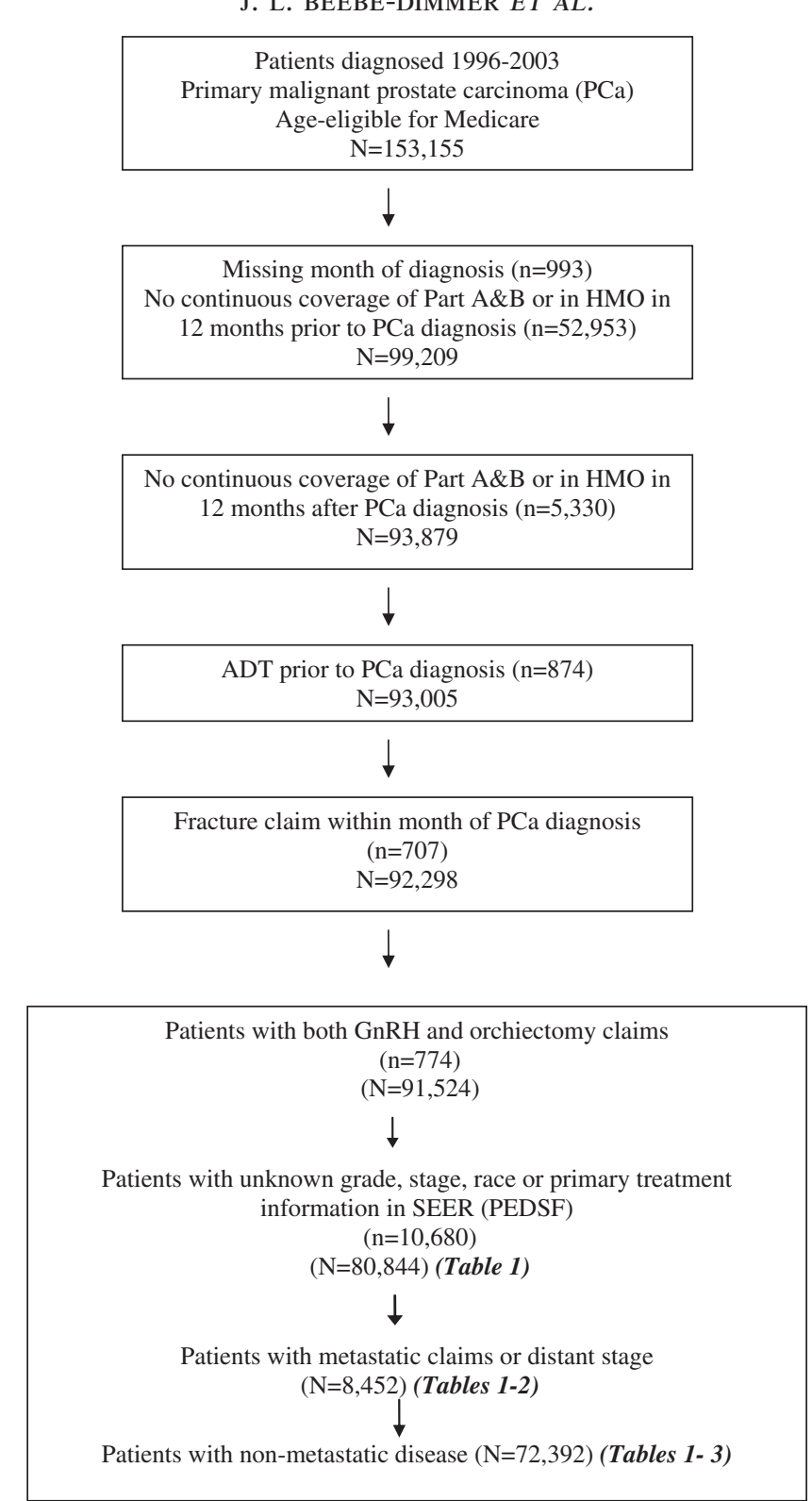

Figure 1. Prostate cancer patients participating in SEER-Medicare study

\section{Statistical methods}

All statistical analyses were performed using the Statistical Analysis Software (SAS Institute Inc. v. 9.1, Cary, NC). We calculated the proportion of patients receiving ADT as part of their treatment according to various baseline characteristics. We estimated both the incidence of fracture (with $95 \%$ confidence intervals [CIs]) for all patients combined and according to ADT treatment, standardized to the age distribution of non-ADT patients. Likewise, the estimated rate associated with ADT was calculated for the three most common sites of fracture (rib, hip, and spine). Cox proportional hazards regression was used to estimate adjusted hazard ratios (aHRs) and 95\%CIs associated with ADT controlling for potential confounders. ADT was treated as a time-dependent covariate (i.e., patients were not considered exposed until the date of first receipt of a GnRH agonist or orchiectomy). The outcome was the time (in months) to fracture or censoring. Prostate cancer patients with no fracture claim during follow-up were censored at (i) death, (ii) loss of or change in Medicare coverage, or (iii) 31 December 2006-whichever came first. Final models 
included age at diagnosis, race, history of fracture, osteoporosis or osteopenia, Charlson comorbidity index, tumor grade, stage, primary treatment (radiation or prostatectomy), and use of intravenous (IV) bisphosphonates (among metastatic patients). Fracture analyses were further stratified to examine ADT effects separately among patients with and without metastatic disease, determined from data collected from either SEER or evidence of bone metastases extracted from claims files. When the findings related to ADT were similar in patients with and without metastatic disease, we opted to present only those findings for men with non-metastatic disease. However, when the findings were deemed different among men with metastatic disease, the aHRs are presented separately. To capture the effect of the timing of ADT and the cumulative dosage on fracture incidence, a time-dependent covariate was created that took into account the time from last treatment (TFLT) in months. The TFLT was equal to 0 if the patient was on ADT during the month of consideration and increased by one for each month off treatment unless treatment resumed, in which case TFLT once again equaled 0 . This information was then combined with the cumulative (CUM) dosage of ADT up to the month of interest using methodology recommended to capture multiple characteristics of a single exposure. ${ }^{22}$ For example, TFLT6CUM10 would indicate 6 months from the patient's last GnRH agonist dose, with a total of 10 doses at that particular point. We estimated hazard ratios for each combined exposure category relative to the reference group (men without ADT). Last, we used Cox regression to estimate the mortality rate associated with (i) any fracture and (ii) fracture requiring hospitalization, treating each as a time-dependent predictor, adjusting for potential confounders (i.e., age, race, year of diagnosis, tumor grade, stage, comorbidities, and primary treatment).

\section{RESULTS}

Of the 80844 prostate cancer patients diagnosed at the age of 66 years and older included in this investigation, $14905(18.4 \%)$ experienced at least one fracture during the course of follow-up, with 3340 (4.1\%) having a fracture that required hospitalization. Nearly $53 \%$ of patients in the study received some form of ADT after their prostate cancer diagnosis (Table 1), with $51 \%$ of patients on GnRH agonists and $2 \%$ of patients undergoing orchiectomy. ADT use was positively associated with age at diagnosis, with $\sim 40 \%$ of patients aged 66 to 69 years receiving some form of ADT, compared with nearly $70 \%$ of patients diagnosed at the age of 80 years and older. The prevalence of use varied depending upon year of diagnosis, increasing from approximately $49 \%$ of patients diagnosed in 1996 to $57 \%$ of patients diagnosed in 2000, and then declining through 2003. ADT use was more common among patients with one or more conditions captured by the Charlson index, among patients with advanced stage and/or aggressive grade disease and, as expected, among patients electing radiation therapy as their primary treatment or no definitive treatment. The use of IV bisphosphonates prior to fracture in this population was low overall $(2.3 \%)$ and differed by the presence of distant metastases $(0.6 \%$ in non-metastatic patients and $18.2 \%$ in metastatic patients). This was expected given the timing of the study period relative to the approval of zoledronic acid by the US Food and Drug Administration for the treatment of bone metastases from solid tumors. ${ }^{23}$

The age-standardized incidence of fracture was higher among ADT users than that among non-users. The fracture rate among patients receiving at least one dose of a GnRH agonist was 57 per 1000 persons per year $(95 \% \mathrm{CI}=56-58)$ compared with 31 per 1000 persons per year $(95 \% \mathrm{CI}=30-32)$ among non-users. The fracture rate among orchiectomy patients was 76 per 1000 persons per year $(95 \% \mathrm{CI}=68-84)$.

Among non-metastatic patients, GnRH agonist use, treated as a time-dependent dichotomous variable, was associated with a $34 \%$ increase in the rate of any fracture $(\mathrm{HR}=1.34 ; 95 \% \mathrm{CI}=1.29-1.39)$, and a positive dose-response relation was observed between fracture incidence and the cumulative number of GnRH doses received over the study period (Table 2). A slightly higher increase in fracture incidence associated with ADT use was observed among men with metastatic disease $(\mathrm{aHR}=1.51 ; 95 \% \mathrm{CI}=1.36-1.67)$. Again, aHRs increased with increasing GnRH dose. Orchiectomy was associated with a $62 \%$ increase in risk of any fracture $(\mathrm{aHR}=1.62 ; 95 \% \mathrm{CI}=1.42-1.84)$ among non-metastatic patients and a $54 \%$ increase in risk among metastatic patients $(\mathrm{aHR}=1.54 ; 95 \% \mathrm{CI}=$ 1.26-1.88). The three most common sites of first-time fracture among patients in the study were rib (17.5\%), hip (16.5\%), and spine (14.6\%), but the elevation in incidence associated with ADT use did not differ appreciably by site (data not shown).

Among non-metastatic patients using GnRH agonists, the incidence rate of fracture was positively associated with cumulative ADT dose and inversely related to the number of months since last use (Table 3). Thus, the fracture risk was highest among patients receiving at least 18 doses of an agonist who were either currently on or who had stopped 
Table 1. Frequency distributions of patient characteristics in SEER-Medicare study of androgen deprivation therapy and fracture risk in men with prostate cancer

\begin{tabular}{|c|c|c|c|c|c|c|c|c|c|}
\hline \multirow[b]{2}{*}{ Characteristic } & \multicolumn{3}{|c|}{ All } & \multicolumn{3}{|c|}{ Non-metastatic } & \multicolumn{3}{|c|}{ Metastatic } \\
\hline & $n$ & $(\%)^{*}$ & $\begin{array}{c}\text { Proportion on } \\
\text { ADT }(\%)\end{array}$ & $n$ & $(\%)^{*}$ & $\begin{array}{c}\text { Proportion on } \\
\text { ADT }(\%)\end{array}$ & $n$ & $(\%)^{*}$ & $\begin{array}{c}\text { Proportion on } \\
\text { ADT }(\%)\end{array}$ \\
\hline Total & 80844 & & 52.8 & 72392 & 89.5 & 49.9 & 8452 & 10.5 & 77.6 \\
\hline \multicolumn{10}{|l|}{ Age (in years) } \\
\hline $66-69$ & 20453 & 25.3 & 39.3 & 18754 & 25.9 & 36.5 & 1699 & 20.1 & 70.2 \\
\hline $70-74$ & 26418 & 32.7 & 49.7 & 23782 & 32.9 & 47.0 & 2636 & 31.2 & 74.0 \\
\hline $75-79$ & 20256 & 25.1 & 59.8 & 18049 & 24.9 & 57.2 & 2207 & 26.1 & 80.6 \\
\hline$\geq 80$ & 13717 & 17.0 & 68.5 & 11807 & 16.3 & 65.7 & 1910 & 22.6 & 85.7 \\
\hline \multicolumn{10}{|l|}{ Race } \\
\hline White & 66005 & 81.6 & 52.4 & 59595 & 82.3 & 49.5 & 6410 & 75.8 & 79.2 \\
\hline Black & 7478 & 9.2 & 50.5 & 6373 & 8.8 & 48.1 & 1105 & 13.1 & 64.3 \\
\hline Other & 7361 & 9.1 & 58.1 & 6424 & 8.9 & 54.6 & 937 & 11.1 & 82.1 \\
\hline \multicolumn{10}{|l|}{ Year of diagnosis } \\
\hline 1996 & 6509 & 8.1 & 49.1 & 5391 & 7.4 & 44.5 & 1118 & 13.2 & 71.3 \\
\hline 1997 & 6699 & 8.3 & 50.1 & 5641 & 7.8 & 46.1 & 1058 & 12.5 & 71.4 \\
\hline 1998 & 6385 & 7.9 & 52.3 & 5518 & 7.6 & 48.9 & 867 & 10.3 & 73.6 \\
\hline 1999 & 6965 & 8.6 & 53.9 & 6084 & 8.4 & 50.4 & 881 & 10.4 & 78.1 \\
\hline 2000 & 12638 & 15.6 & 56.6 & 11342 & 15.7 & 53.6 & 1296 & 15.3 & 83.0 \\
\hline 2001 & 13763 & 17.0 & 54.5 & 12565 & 17.4 & 51.9 & 1198 & 14.2 & 81.3 \\
\hline 2002 & 14393 & 17.8 & 52.1 & 13294 & 18.4 & 49.7 & 1099 & 13.0 & 81.4 \\
\hline 2003 & 13492 & 16.7 & 50.8 & 12557 & 17.3 & 48.7 & 935 & 11.1 & 78.7 \\
\hline \multicolumn{10}{|l|}{$<12$ years of education ${ }^{\dagger}$} \\
\hline$<10 \%$ & 27233 & 33.7 & 49.4 & 24778 & 34.2 & 46.5 & 2455 & 29.0 & 79.3 \\
\hline $10 \%$ to $<20 \%$ & 28312 & 35.0 & 53.6 & 25385 & 35.1 & 50.7 & 2927 & 34.6 & 78.7 \\
\hline $20 \%$ to $<30 \%$ & 12571 & 15.6 & 54.3 & 11116 & 15.4 & 51.6 & 1455 & 17.2 & 74.4 \\
\hline$\geq 30 \%$ & 12724 & 15.7 & 56.6 & 11109 & 15.3 & 53.8 & 1615 & 19.1 & 76.0 \\
\hline \multicolumn{10}{|c|}{ Income below the poverty line $e^{\dagger}$} \\
\hline$<3 \%$ & 12124 & 15.0 & 51.7 & 10951 & 15.1 & 48.9 & 1173 & 13.9 & 77.6 \\
\hline $3 \%$ to $<7 \%$ & 26469 & 32.7 & 52.4 & 23802 & 32.9 & 49.5 & 2667 & 31.6 & 78.4 \\
\hline $7 \%$ to $<14 \%$ & 21762 & 26.9 & 52.6 & 19591 & 27.1 & 49.7 & 2171 & 25.7 & 78.7 \\
\hline$\geq 14 \%$ & 20485 & 25.3 & 54.0 & 18044 & 24.9 & 51.1 & 2441 & 28.9 & 75.8 \\
\hline \multicolumn{10}{|c|}{ Charlson comorbidity index } \\
\hline 0 & 59617 & 73.7 & 50.9 & 53429 & 73.8 & 47.8 & 6188 & 73.2 & 78.0 \\
\hline 1 & 14801 & 18.3 & 57.0 & 13259 & 18.3 & 54.7 & 1542 & 18.2 & 76.0 \\
\hline 2 & 4261 & 5.3 & 59.8 & 3792 & 5.2 & 57.4 & 469 & 5.5 & 79.1 \\
\hline+3 & 2166 & 2.7 & 60.4 & 1913 & 2.6 & 58.4 & 253 & 3.0 & 75.5 \\
\hline \multicolumn{10}{|l|}{ Grade of prostate cancer } \\
\hline Well differentiated & 4475 & 5.5 & 35.9 & 4225 & 5.8 & 34.7 & 250 & 3.0 & 56.0 \\
\hline $\begin{array}{l}\text { Moderately } \\
\text { differentiated }\end{array}$ & 55710 & 68.9 & 47.4 & 51538 & 71.2 & 45.6 & 4172 & 49.4 & 69.7 \\
\hline Poorly differentiated & 20659 & 25.6 & 70.9 & 16629 & 23.0 & 67.0 & 4030 & 47.7 & 87.1 \\
\hline \multicolumn{10}{|l|}{ Clinical T stage } \\
\hline I & 30423 & 37.6 & 45.2 & 28417 & 39.3 & 43.8 & 2006 & 23.7 & 66.1 \\
\hline II & 45526 & 56.3 & 54.5 & 41938 & 57.9 & 52.6 & 3588 & 42.5 & 76.5 \\
\hline III & 2009 & 2.5 & 79.8 & 1676 & 2.3 & 77.5 & 333 & 3.9 & 91.6 \\
\hline IV & 2886 & 3.6 & 85.7 & 361 & 0.5 & 80.1 & 2525 & 29.9 & 86.5 \\
\hline \multicolumn{10}{|l|}{ SEER summary stage } \\
\hline Local/Regional & 78382 & 97.0 & 51.7 & 72392 & 100.0 & 49.9 & 5990 & 70.9 & 74.1 \\
\hline Distant & 2462 & 3.0 & 86.2 & & 0.0 & & 2462 & 29.1 & 86.2 \\
\hline \multicolumn{10}{|c|}{ Other treatment within 6 months of diagnosis } \\
\hline Neither & 30035 & 37.2 & 60.8 & 25512 & 35.2 & 56.6 & 4523 & 53.5 & 84.2 \\
\hline Radiation & 36545 & 45.2 & 58.1 & 33421 & 46.2 & 56.6 & 3124 & 37.0 & 74.6 \\
\hline $\begin{array}{l}\text { Radical } \\
\text { prostatectomy }\end{array}$ & 13605 & 16.8 & 20.8 & 12885 & 17.8 & 19.2 & 720 & 8.5 & 48.6 \\
\hline Both & 659 & 0.8 & 52.2 & 574 & 0.8 & 48.3 & 85 & 1.0 & 78.8 \\
\hline
\end{tabular}

SEER, Surveillance, Epidemiology, and End Results; ADT, androgen deprivation therapy.

*Percentages may not sum $100 \%$ due to rounding.

${ }^{\dagger}$ This refers to the census tract in which the patient resided at the time of diagnosis and the proportion of residents within the tract with fewer than 12 years of education or household income below the poverty line (four missing).

therapy in the past 6 months (compared with men who had not used ADT, $\mathrm{aHR}=1.67 ; 95 \% \mathrm{CI}=$ 1.56-1.78). Conversely, the fracture risk was almost the same for men who had received fewer than six doses more than 18 months ago and men who had not received any ADT $(\mathrm{aHR}=1.06 ; 95 \% \mathrm{CI}=$ 
Table 2. Adjusted hazard ratio* (and 95\%CI) for fracture risk associated with ADT among elderly men diagnosed with prostate cancer $(n=80844)$

\begin{tabular}{llclll}
\hline & \multicolumn{2}{c}{ All fractures } & & \multicolumn{2}{c}{ Fractures requiring hospitalization } \\
\cline { 2 - 3 } & Non-metastatic & Metastatic & & Non-metastatic & \multicolumn{1}{c}{ Metastatic } \\
\hline No ADT & 1.00 & 1.00 & 1.00 & 1.00 \\
Gonadotropin-releasing hormone agonist & $1.34(1.29-1.39)$ & $1.51(1.36-1.67)$ & & $1.34(1.26-1.43)$ & $1.58(1.35-1.85)$ \\
$1-5$ doses & $1.21(1.15-1.27)$ & $1.22(1.07-1.39)$ & & $1.11(1.02-1.22)$ & $1.12(0.90-1.40)$ \\
$6-17$ doses & $1.31(1.25-1.38)$ & $1.48(1.31-1.68)$ & & $1.29(1.19-1.40)$ & $1.49(1.24-1.81)$ \\
$\geq 18$ doses & $1.66(1.57-1.76)$ & $1.99(1.75-2.27)$ & & $1.74(1.59-1.90)$ & $2.20(1.82-2.67)$ \\
Orchiectomy & $1.62(1.42-1.84)$ & $1.54(1.26-1.88)$ & & $1.87(1.56-2.25)$ & $1.63(1.21-2.18)$ \\
\hline
\end{tabular}

CI, confidence interval; ADT, androgen deprivation therapy.

*Hazard ratios were adjusted for age at prostate cancer diagnosis, race, tumor grade, clinical T stage, presence of comorbidities, history of fracture, osteoporosis or osteopenia prior to prostate cancer diagnosis, and primary treatment. Analyses among metastatic patients were additionally adjusted for intravenous bisphosphonate use.

${ }^{\dagger}$ Cumulative dose from diagnosis until fracture or censoring event.

Table 3. Risk of fracture associated with dose and recency of GnRH agonist use among men with non-metastatic prostate cancer $(n=72392)$

\begin{tabular}{lcccc}
\hline & \multicolumn{4}{c}{ Months since last GnRH agonist dose } \\
\cline { 2 - 5 } & $0-6$ months & $7-12$ months & $13-18$ months & $\geq 19$ months \\
\hline Cumulative dose & aHR (95\%CI) & aHR (95\%CI) & aHR (95\%CI) & aHR (\%\%CI) \\
$1-5$ doses & $1.43(1.32-1.56)$ & $1.26(1.08-1.46)$ & $1.24(1.06-1.45)$ & $1.06(0.99-1.14)$ \\
$6-17$ doses & $1.58(1.47-1.69)$ & $1.46(1.28-1.65)$ & $1.00-1.35)$ & $1.04(0.96-1.13)$ \\
$\geq 18$ doses & $1.67(1.56-1.78)$ & $1.58(1.33-1.87)$ & $1.32-2.01)$ & $1.16-1.58)$ \\
\hline
\end{tabular}

GnRH, gonadotropin-releasing hormone; aHR, adjusted hazard ratio; CI, confidence interval.

aHR: hazard ratio using Cox regression adjusting for age at diagnosis, race, history of bone-related complications, presence of comorbidities, tumor grade, clinical T stage, and primary treatment.

*Referent group: patients not receiving any androgen deprivation therapy.

0.99-1.14). Similar trends were observed among metastatic patients (data not shown).

Among men with non-metastatic disease, the mortality risks within 6 and 12 months of experiencing any fracture were $8.3 \%$ and $12.2 \%$, respectively. Fracture was associated with a more than twofold increase in the rate of death $(\mathrm{aHR}=2.05 ; 95 \% \mathrm{CI}=1.98-2.12)$ after adjusting for age at diagnosis, year of diagnosis, race, the presence of one or more comorbidities prior to diagnosis, tumor grade, stage, and initial treatment. The occurrence of a fracture that required hospitalization was associated with a nearly threefold increase in the rate of death $(\mathrm{aHR}=2.82 ; 95 \% \mathrm{CI}=2.68-2.97)$ after adjusting for the same prognostic covariates.

\section{DISCUSSION}

In this large, population-based investigation of elderly men with prostate cancer, we observed that the use of ADT was associated with a $34 \%$ increase in fracture incidence and that the rate increased with cumulative dose (among men on GnRH agonists). Our results are consistent with prior reports linking ADT to fracture in men with prostate cancer. ${ }^{2,3,16}$ Our study is the first to report an inverse relationship between rate of fracture and the time since last use of GnRH agonists. In addition, we found that fracture occurrence after prostate cancer diagnosis was associated with excess mortality among men with non-metastatic disease, particularly when that fracture resulted in hospitalization.

Recent concepts about osteoporotic fracture incorporate the effect of increased bone turnover on impairment of bone strength, independent of reduced bone mineral density. ${ }^{24}$ This is supported by results of trials of antiresorptive therapies in postmenopausal women that demonstrated fracture risk reduction that could not be fully explained by improvements in bone mineral density. ${ }^{25}$ Androgen deprivation, through the induction of testosterone, and more importantly, estrogen deficiency, increases bone turnover and bone resorption, eventually leading to declines in bone mineral density. ${ }^{26,27}$ Our findings are consistent with this current understanding of the pathophysiology of osteoporotic fracture risk. The increased rate of fracture in men receiving only a few doses of GnRH agonists, which then returns to normal over time after discontinuation of therapy, may predominantly represent the effect of androgen deprivation on bone turnover. In 
contrast, the even higher fracture rate in men on longterm therapy, which persists after discontinuation, may represent the additional effect of a profound reduction in bone mineral density.

There is still controversy about whether to prescribe long-term ( 2 to 3 years) or shorter (6 month) courses for men with locally advanced or high-risk disease with an indication for adjuvant ADT coupled with radiotherapy. Although in the clinical trial setting a longer duration of ADT leads to better overall and prostate-cancer-specific survival, ${ }^{28}$ our findings suggest that it would also be associated with a higher and persistent risk of fracture, as compared with a shorter course of therapy. Because even short courses of adjuvant ADT with radiation improve overall and prostate-cancer-specific survival, ${ }^{29}$ men with a medical history that places them at a high risk of fracture may wish to consider shorter courses of ADT to limit that risk.

The excess in the death rates observed among men with non-metastatic prostate cancer who experience a fracture is consistent with other hospital- and population-based investigations of fracture and mortality. ${ }^{30-35}$ The incidence of hip fracture in the Medicare population has declined among men in the past decade, as has its associated mortality. ${ }^{36}$ However, both the absolute and relative mortality risk rates associated with hip fracture are higher among men compared with women. ${ }^{30,33,34}$ Risk of death is greatest in the days and weeks following fracture; however, it can remain elevated for months and even years. ${ }^{30,31}$ There is continued concern about increased mortality due to nonprostate-cancer-related causes among patients on ADT, particularly among men with a history of cardiovascular disease. ${ }^{37-39}$ Our results indicate that fracture also contributes to the excess in non-cancer mortality.

There are limitations worth noting in the current investigation. Confounding by indication is an important concern in observational studies examining the effect of treatment on an outcome. ${ }^{40}$ Our findings indicate that ADT was used more frequently among prostate cancer patients with aggressive-grade and distant-stage disease. Because the presence of bony metastases increases fracture risk independently of treatment, ${ }^{41}$ we stratified analyses and examined the associations with ADT separately among patients with and without evidence of metastatic disease, either at the time of diagnosis or at any point over follow-up. The observed hazard ratios associated with use of $\mathrm{GnRH}$ agonists were similar between groups for both any fracture and hospitalized fractures. In addition, the potential for residual confounding is an important consideration stemming from the observational nature of the investigation and the lack of complete information on all confounding factors. Therefore, our adjustment for comorbidities and available confounding variables in the analysis is likely incomplete.

Medicare data are limited to some degree due to the potential for missing information on services that are either not covered by Medicare or not billed to Medicare. For this reason, we excluded patients participating in an HMO in the 12 months prior to diagnosis and censored patients at the time of any change or loss in Medicare coverage over the course of study. The exclusion of HMO enrollees may limit the generalizability of our findings because HMO enrollees tend to be younger and healthier than Medicare beneficiaries. ${ }^{42}$ A comparison of the baseline characteristics of patients excluded for incomplete Medicare coverage with those included in the analysis indicated that distributions were similar between groups (results not shown). An assessment of the representativeness of SEER patients included in the SEER-Medicare database with the elderly US population indicates that although the age and gender distribution is comparable, a greater proportion of SEER-Medicare patients belong to other minority (non-Black, non-White) groups and reside in urban areas. ${ }^{42}$ Last, these findings are not necessarily generalizable to patients diagnosed with prostate cancer before the age of 65 years.

\section{CONCLUSIONS}

This study reconfirms the link between ADT and fracture incidence in elderly men with prostate cancer. Moreover, our results also indicate a reduction in fracture rates with an increasing amount of time since last use, irrespective of the cumulative dose, among men on GnRH agonists. Because our investigation also shows an association between fracture and mortality in these men, it is particularly important for clinicians to communicate the benefits and possible risks of androgen deprivation to patients and review strategies to reduce the potential adverse consequences of therapy.

\section{CONFLICT OF INTEREST}

Amgen Inc. provided the funds to support this research project. This project was intended to fill a gap in the published literature describing the burden of fracture among elderly men with prostate cancer and associated mortality. Dr. Acquavella and Ms. Cetin (employees of the sponsor), acting as collaborators on the study, were involved in the design, analysis, and interpretation of the data and in the writing of the article. 


\section{KEY POINTS}

- Fracture is a recognized consequence of ADT use; however, the mortality risk associated with fracture in men with prostate cancer has never been estimated in a large-scale investigation.

- Conditional on cumulative dose, the risk of fracture associated with ADT use in elderly men with prostate cancer declines with an increasing number of months since last use of a GnRH agonist, a finding not previously reported.

- Our findings suggest that careful monitoring of elderly patients on ADT is crucial, and continuous, long-term use may have serious adverse consequences for these men.

\section{ACKNOWLEDGEMENTS}

The authors acknowledge The SEER-Medicare Program Office (http://healthservices.cancer.gov/seermedicare/ obtain/use.html).

This work was supported by Amgen Inc. Thousand Oaks, CA 91320.

\section{REFERENCES}

1. Higano CS. Androgen-deprivation-therapy-induced fractures in men with nonmetastatic prostate cancer: what do we really know? Nat Clin Pract Urol 2008 Jan; 5(1): 24-34.

2. Shahinian VB, Kuo YF, Freeman JL, Goodwin JS. Risk of fracture after androgen deprivation for prostate cancer. $N$ Engl J Med 2005 Jan 13; 352(2): 154-164.

3. Smith MR, Lee WC, Brandman J, Wang Q, Botteman M, Pashos CL. Gonadotropin-releasing hormone agonists and fracture risk: a claims-based cohort study of men with nonmetastatic prostate cancer. J Clin Oncol 2005 Nov 1; 23(31): 7897-7903.

4. Keating NL, O'Malley AJ, Smith MR. Diabetes and cardiovascular disease during androgen deprivation therapy for prostate cancer. J Clin Oncol 2006 Sep 20; 24(27): 4448-4456.

5. Gilbert SM, Kuo YF, Shahinian VB. Prevalent and incident use of androgen deprivation therapy among men with prostate cancer in the United States. Urol Oncol 2009 Nov 17. [Epub ahead of print].

6. Maillefert JF, Sibilia J, Michel F, Saussine C, Javier RM, Tavernier C. Bone mineral density in men treated with synthetic gonadotropin-releasing hormone agonists for prostatic carcinoma. J Urol 1999 Apr; 161(4): 1219-1222.

7. Mittan D, Lee S, Miller E, Perez RC, Basler JW, Bruder JM. Bone loss following hypogonadism in men with prostate cancer treated with GnRH analogs. J Clin Endocrinol Metab 2002 Aug; 87(8): 3656-3661.

8. Berruti A, Dogliotti L, Terrone C, Cerutti S, Isaia G, Tarabuzzi R, et al. Changes in bone mineral density, lean body mass and fat content as measured by dual energy $\mathrm{x}$-ray absorptiometry in patients with prostate cancer without apparent bone metastases given androgen deprivation therapy. J Urol 2002 Jun; 167(6): 2361-2367.

9. Greenspan SL, Nelson JB, Trump DL, Resnick NM. Effect of once-weekly oral alendronate on bone loss in men receiving androgen deprivation therapy for prostate cancer: a randomized trial. Ann Intern Med 2007 Mar 20; 146(6): 416-424.

10. Smith MR, McGovern FJ, Zietman AL, Fallon MA, Hayden DL, Schoenfeld DA, et al. Pamidronate to prevent bone loss during androgen-deprivation therapy for prostate cancer. $N$ Engl J Med 2001 Sep 27; 345(13): 948-955.

11. Smith MR, Eastham J, Gleason DM, Shasha D, Tchekmedyian S, Zinner N. Randomized controlled trial of zoledronic acid to prevent bone loss in men receiving androgen deprivation therapy for nonmetastatic prostate cancer. J Urol 2003 Jun; 169(6): 2008-2012.
12. Israeli RS, Rosenberg SJ, Saltzstein DR, Gottesman JE, Goldstein HR, Hull GW, et al. The effect of zoledronic acid on bone mineral density in patients undergoing androgen deprivation therapy. Clin Genitourin Cancer 2007 Mar; 5(4): 271-277.

13. Smith MR, Egerdie B, Hernandez TN, Feldman R, Tammela TL, Saad F, et al. Denosumab in men receiving androgen-deprivation therapy for prostate cancer. N Engl J Med 2009 Aug 20; 361(8): 745-755.

14. Vanderwalde A, Hurria A. Aging and osteoporosis in breast and prostate cancer. CA Cancer J Clin 2011 May; 61(3): 139-156.

15. Ryan CW, Huo D, Demers LM, Beer TM, Lacerna LV. Zoledronic acid initiated during the first year of androgen deprivation therapy increases bone mineral density in patients with prostate cancer. J Urol 2006 Sep; 176(3): 972-978.

16. Smith MR, Boyce SP, Moyneur E, Duh MS, Raut MK, Brandman J. Risk of clinical fractures after gonadotropin-releasing hormone agonist therapy for prostate cancer. J Urol 2006 Jan; 175(1): 136-139.

17. Ahlborg HG, Nguyen ND, Center JR, Eisman JA, Nguyen TV. Incidence and risk factors for low trauma fractures in men with prostate cancer. Bone 2008 Sep; 43(3): 556-560.

18. Abrahamsen B, Nielsen MF, Eskildsen P, Andersen JT, Walter S, Brixen K Fracture risk in Danish men with prostate cancer: a nationwide register study. BJU Int 2007 Oct; 100(4): 749-754.

19. Potosky AL, Riley GF, Lubitz JD, Mentnech RM, Kessler LG. Potential for cancer related health services research using a linked Medicare-tumor registry database. Med Care 1993 Aug; 31(8): 732-748.

20. Klabunde CN, Warren JL, Legler JM. Assessing comorbidity using claims data: an overview. Med Care 2002 Aug; 40(8 Suppl): IV-35.

21. Bach PB, Guadagnoli E, Schrag D, Schussler N, Warren JL. Patient demographic and socioeconomic characteristics in the SEER-Medicare database applications and limitations. Med Care 2002 Aug; 40(8 Suppl): IV-25.

22. McKnight B, Cook LS, Weiss NS. Logistic regression analysis for more than one characteristic of exposure. Am J Epidemiol 1999 Jun 1; 149(11): 984-992.

23. Ibrahim A, Scher N, Williams G, Sridhara R, Li N, Chen G, et al. Approval summary for zoledronic acid for treatment of multiple myeloma and cancer bone metastases. Clin Cancer Res 2003 Jul; 9(7): 2394-2399.

24. Burr DB. Introduction--Bone turnover and fracture risk. J Musculoskelet Neuronal Interact 2003 Dec; 3(4): 408-409.

25. Cefalu CA. Is bone mineral density predictive of fracture risk reduction? Curr Med Res Opin 2004 Mar; 20(3): 341-349.

26. Manolagas SC, Weinstein RS. New developments in the pathogenesis and treatment of steroid-induced osteoporosis. J Bone Miner Res 1999 Jul; 14(7): 1061-1066.

27. Riggs BL, Khosla S, Melton LJ, III. Sex steroids and the construction and conservation of the adult skeleton. Endocr Rev 2002 Jun; 23(3): 279-302.

28. Bolla M, de Reijke TM, Van TG, Van den Bergh AC, Oddens J, Poortmans PM, et al. Duration of androgen suppression in the treatment of prostate cancer. $N$ Engl J Med 2009 Jun 11; 360(24): 2516-2527.

29. D'Amico AV, Manola J, Loffredo M, Renshaw AA, DellaCroce A, Kantoff PW. 6-month androgen suppression plus radiation therapy vs radiation therapy alone for patients with clinically localized prostate cancer: a randomized controlled trial. JAMA 2004 Aug 18; 292(7): 821-827.

30. Abrahamsen B, van ST, Ariely R, Olson M, Cooper C. Excess mortality following hip fracture: a systematic epidemiological review. Osteoporos Int 2009 Oct; 20(10): 1633-1650.

31. Haentjens P, Magaziner J, Colon-Emeric CS, Vanderschueren D, Milisen K, Velkeniers B, et al. Meta-analysis: excess mortality after hip fracture among older women and men. Ann Intern Med 2010 Mar 16; 152(6): 380-390.

32. Bliuc D, Nguyen ND, Milch VE, Nguyen TV, Eisman JA, Center JR. Mortality risk associated with low-trauma osteoporotic fracture and subsequent fracture in men and women. JAMA $2009 \mathrm{Feb} 4 ;$ 301(5): 513-521.

33. Trombetti A, Herrmann F, Hoffmeyer P, Schurch MA, Bonjour JP, Rizzoli R. Survival and potential years of life lost after hip fracture in men and age-matched women. Osteoporos Int 2002 Sep; 13(9): 731-737.

34. Forsen L, Sogaard AJ, Meyer HE, Edna T, Kopjar B. Survival after hip fracture: short- and long-term excess mortality according to age and gender. Osteoporos Int 1999; 10(1): 73-78.

35. Oefelein MG, Ricchiuti V, Conrad W, Resnick MI. Skeletal fractures negatively correlate with overall survival in men with prostate cancer. J Urol 2002 Sep; 168(3): 1005-1007.

36. Brauer CA, Coca-Perraillon M, Cutler DM, Rosen AB. Incidence and mortality of hip fractures in the United States. JAMA 2009 Oct 14; 302(14): 1573-1579.

37. D'Amico AV, Chen MH, Renshaw AA, Loffredo M, Kantoff PW. Causes of death in men undergoing androgen suppression therapy for newly diagnosed localized or recurrent prostate cancer. Cancer 2008 Dec 15; 113(12): 3290-3297.

38. Hayes JH, Chen MH, Moran BJ, Braccioforte MH, Dosoretz DE, Salenius S, et al. Androgen-suppression therapy for prostate cancer and the risk of death in men with a history of myocardial infarction or stroke. BJU Int 2010 Oct; 106(7): 979-985.

39. Levine GN, D'Amico AV, Berger P, Clark PE, Eckel RH, Keating NL, et al. Androgen-deprivation therapy in prostate cancer and cardiovascular risk: 
a science advisory from the American Heart Association, American Cancer Society, and American Urological Association: endorsed by the American Society for Radiation Oncology. Circulation 2010 Feb 16; 121(6): 833-840.

40. Salas M, Hofman A, Stricker BH. Confounding by indication: an example of variation in the use of epidemiologic terminology. Am J Epidemiol 1999 Jun 1; 149(11): 981-983.
41. Berruti A, Dogliotti L, Bitossi R. Incidence of skeletal complications in patients with bone metastastic prostate cancer and hormone refractory disease: predictive role of bone resorption and formation markers at baseline. J Urol 2000; 164: $1248-1253$.

42. Warren JL, Klabunde CN, Schrag D, Bach PB, Riley GF. Overview of the SEER-Medicare data: content, research applications, and generalizability to the United States elderly population. Med Care 2002 Aug; 40(8 Suppl): IV-18. 